\title{
Epilepsy, neuropsychiatric phenotypes, neuroimaging findings, and genotype-neurophenotype correlation in 22q11.2 deletion syndrome
}

Heeba Y. AlKalaf, MD, Amal M. AlHashem, MD, Norah S. AlSaleh, MD, Norah M. AlJohar, MSS, Aliyah M. Abo Thneen, BA, Hatem M. ElGhezal, MD, PhD, Inesse B. Bouhjar, PhD, Kalthoum Tlili-Graiess, MD, Atif H. Sahari, MD, Brahim M. Tabarki, $M D$.

\section{ABSTRACT}

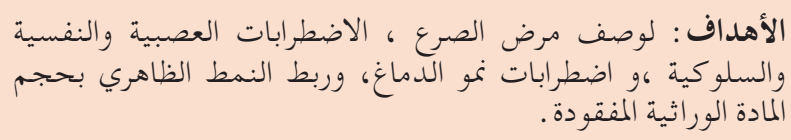

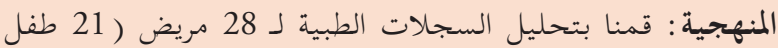

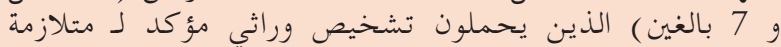

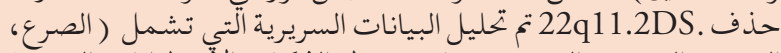

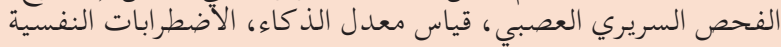

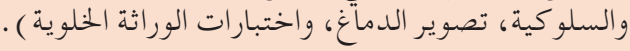

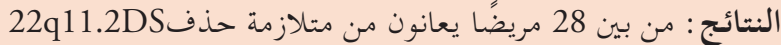

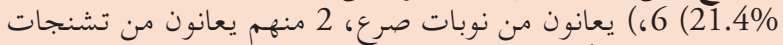

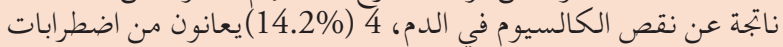

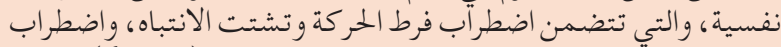

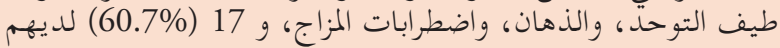

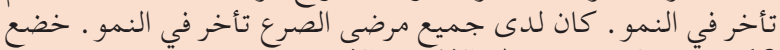

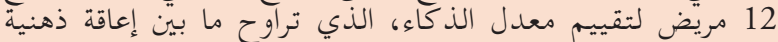

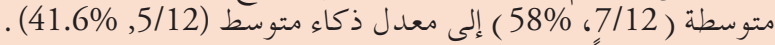

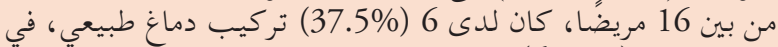

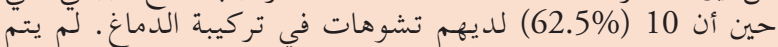

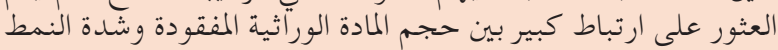

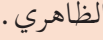

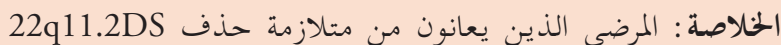

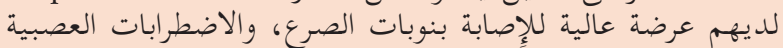

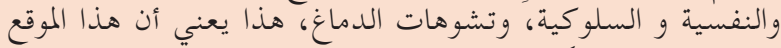

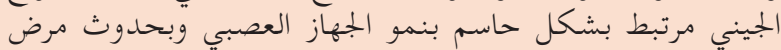
الصرع

Objectives: To describe the epilepsy, neuropsychiatric manifestations, and neuroimaging findings in a group of patients with $22 \mathrm{q} 11.2 \mathrm{DS}$, and to correlate the size of the deleted genetic material with the severity of the phenotype.

Methods: We retrospectively analyzed the medical records of 28 patients ( 21 pediatric patients and 7 adults) with a genetically confirmed diagnosis of 22q11.2 DS. Clinical data (epilepsy, neurological exam, neuropsychological and developmental assessment, and psychiatric disorders), neuroimaging, and cytogenetic tests were analyzed.

Results: Of the 28 patients with 22 q11.2 DS, 6 $(21.4 \%)$ had epileptic seizures, 2 had symptomatic hypocalcemic seizures, $4(14.2 \%)$ had a psychiatric disorder, which comprised of attention deficit hyperactivity disorder, autism spectrum disorder, psychosis, and mood disorder, and 17 (60.7\%) had developmental delay. All patients with epilepsy had a developmental delay. Twelve patients underwent a neuropsychology assessment. Intellectual levels ranged from moderate intellectual disability $(7 / 12,58 \%)$ to average $(5 / 12,41.6 \%)$. Of the 16 patients, $6(37.5 \%)$ had a normal brain, while $10(62.5 \%)$ had abnormal neuroimaging findings. No significant correlation was found between the size of the deleted genetic material and the severity of the phenotype.

Conclusion: $22 \mathrm{q} 11.2 \mathrm{DS}$ patients are at high risk to develop epilepsy, neuropsychiatric manifestations, and structural brain abnormalities. This indicates that this defined genetic locus is crucial for the development of the nervous system, and patients with 22q11.2 DS have genetic susceptibility to develop epilepsy.

Neurosciences 2020; Vol. 25 (4): 287-291 doi: 10.17712/nsj.2020.4.20200045

From the Division of Pediatric Neurology (AlKalaf, Tabarki), Division of Genetics (AlHashem, AlSaleh), Department of Pediatrics, Division of Neuropsychology (AlJohar, Abo Thneen), Department of Psychiatry, from the Division of Cytogenetics and Molecular Genetics (ElGhezal, Bouhjar), Department of Laboratory, Division of Neuroradiology (Tlili-Graiess), Department of Radiology, Prince Sultan Military Medical City, from the Department of Pediatric Cardiology (Sahari), Prince Sultan Cardiac Center, and from the Deapartment of Biology (AlHashem), Alfaisal University, Riyadh, Kingdom of Saudi Arabia

Received 23rd March 2020. Accepted 28th April 2020.

Address correspondence and reprint request to: Dr. Brahim Tabarki, Division of Neurology, Department of Pediatrics, Prince Sultan Military Medical City, Riyadh, Kingdom of Saudi Arabia. E-mail:btabarki@hotmail.com

ORCID ID: https://orcid.org/0000-0001-6240-0489 
2 $2 \mathrm{q} 11.2$ deletion syndrome (22q11.2DS) has many names such as velocardiofacial syndrome and DiGeorge syndrome, which is the most common microdeletion syndrome. ${ }^{1}$ It is due to hemizygous microdeletions on chromosome $22 \mathrm{q} 11.2$, it occurs 1 in 4000 live births, and 90\% occur de novo. Most individuals with 22q11.2 DS lost about 3 Megabases $(\mathrm{Mb})$ of DNA on chromosome 22 at position 22 q11.2 in each cell. ${ }^{2}$ Some affected individuals have smaller deleted genetic material in this region. The clinical picture has a markedly different expression and incomplete penetrance. Therefore, 22q11.2DS has symptoms affecting several systems in the body, including congenital heart anomalies, palatal anomalies, hypocalcemia due to hypoplasia of parathyroid glands, immunodeficiency due to hypoplastic thymus, facial dysmorphism, disorders of cognition and behavior, and psychiatric disorders. ${ }^{3}$ However, few studies have been conducted on the epilepsy, neurological, neuroimaging, and neuropsychiatric features of 22q11.2 DS.

This study aimed to examine the epilepsy, neurological, neuropsychiatric phenotypes, and neuroimaging findings in a series of individuals with $22 \mathrm{q} 11.2$ DS and to correlate the genotype with the neurophenotype.

Methods. We retrospectively analyzed the medical records of 28 patients (21 pediatric patients and 7 adults) with a confirmed genetic diagnosis of $22 \mathrm{q} 11.2$ deletion syndrome at the medical genetic clinic, at Prince Sultan Military Medical City in Riyadh, Saudi Arabia, in the period from 01-2019 to 11-2019. The diagnosis of 22q11.2 DS was ascertained using fluorescence in situ hybridization (FISH), array comparative genomic hybridization (aCGH), and whole-exome sequencing. Twenty-one of the (75\%) patients had congenital heart disease, $16 / 28(57.1 \%)$ had undergone surgery, and $2 / 16(12.5 \%)$ had post-surgical complications in the form of ventricular fibrillation, arrhythmia, and seizures.

The patients were evaluated as follows: A neurological examination including the head size, tone, and presence of neurological deficits:

- The presence of epilepsy, epilepsy classification, electroencephalography, and response to antiepileptic medications

- Neuropsychiatric evaluation. Patients were evaluated by a certified neuropsychologist for intelligence quotient (IQ) assessment using the Stanford Binet intelligence scale $5^{\text {th }}$ edition. They were classified as having a mild, moderate, or severe intellectual disability. Patients with psychiatric illness were followed up by the psychiatry clinic
- Neuroimaging studies of the brain (computed tomography or magnetic resonance imaging) were reviewed by a certified pediatric neuroradiologist

- Cytogenetic or molecular karyotyping was performed to define the size of the abrasion and copy number variation and to correlate the genotype with the phenotype

This research has been approved by the Institutional Review Board (IRB) of Prince Sultan Military Medical City, IRB project No.1162/2019.

Results. Epilepsy in 22q11.2 DS. Six of the 28 (21.4\%) patients had epilepsy, and 2 patients had symptomatic hypocalcemic seizures. The epilepsy was classified as focal in three patients and generalized in three patients (Table 1). Five patients had their first seizure during the neonatal or childhood period, and one patient had his first seizure when he was 19 years old. Five $(83.3 \%)$ were classified as having genetic epilepsy, and $1(16.67 \%)$ as having structural epilepsy. The patients with epilepsy were well controlled on monotherapy with antiepileptic medications. All 6 patients with epilepsy had developmental delay, with intellectual functioning ranging from borderline
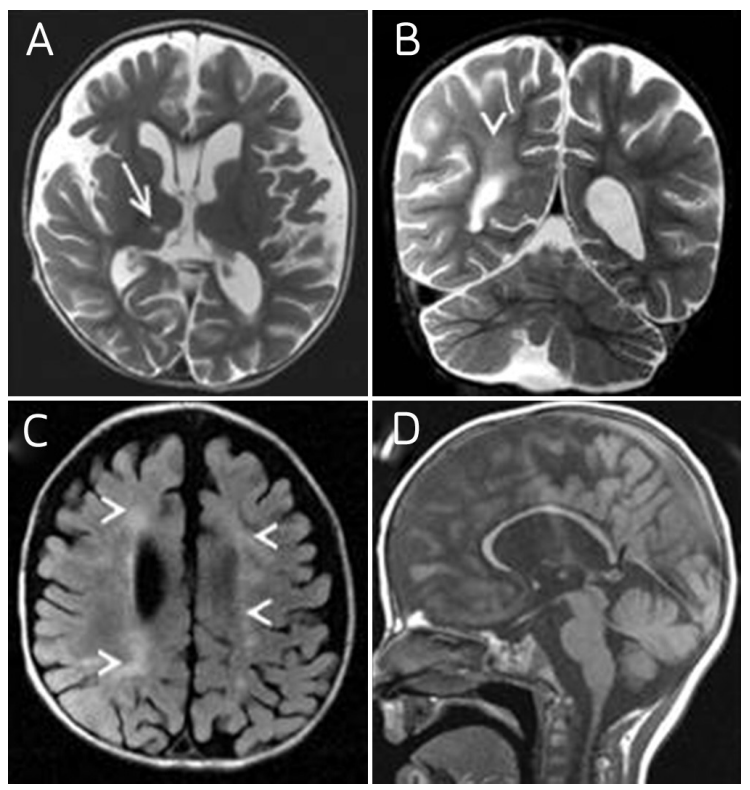

Figure 1 - MRI (Patient 6 in Table 1) at age of 18 months with axial (a) and coronal (b) T2-weighted images, axial fluid-attenuated inversion recovery (c) and sagittal (d) T1-weighted images show supra and infratentorial atrophic changes with scattered white matter abnormalities in the periventricular and deep white matter, tiny lacunar infarct at right thalamus, cavum of the septum pellucidum, and global thinning of the corpus callosum 
Table 1 - Clinical features and EEG finding of 6 patients with 22q11.2 deletion syndrome with epilepsy.

\begin{tabular}{|c|c|c|c|c|c|c|c|c|c|}
\hline $\begin{array}{l}\text { Age/ } \\
\text { sex }\end{array}$ & $\begin{array}{c}\text { Age at } \\
\text { onset of } \\
\text { seizure }\end{array}$ & $\begin{array}{l}\text { seizure } \\
\text { type }\end{array}$ & $\begin{array}{l}\text { EEG } \\
\text { finding }\end{array}$ & $\begin{array}{l}\text { Response } \\
\text { to AED }\end{array}$ & $\begin{array}{l}\text { Brain MRI } \\
\text { findings }\end{array}$ & $\begin{array}{c}\text { Delayed } \\
\text { development }\end{array}$ & $\begin{array}{l}\text { Intellectual } \\
\text { disability }\end{array}$ & $\begin{array}{l}\text { Psychiatric } \\
\text { disorder }\end{array}$ & Deletion size \\
\hline $\begin{array}{l}3 \\
\mathrm{yr} / \mathrm{M}\end{array}$ & 20 days & Focal & G. slow BA & $\begin{array}{c}\text { Well- } \\
\text { controlled } \\
\text { on BZO }\end{array}$ & $\begin{array}{l}\text { Multifocal T2 } \\
\text { HSI in WM, } \\
\text { cerebral atrophy }\end{array}$ & + & $\begin{array}{l}\text { NA(he } \\
\text { died) }\end{array}$ & - & $2.5 \mathrm{Mb}$ \\
\hline $\begin{array}{l}22 \\
y r / M\end{array}$ & 19 years & GTC & G. slow BA & $\begin{array}{l}\text { Well- } \\
\text { controlled } \\
\text { on LEV }\end{array}$ & $\begin{array}{c}\text { Superior } \\
\text { cerebellar vermis } \\
\text { hypoplasia }\end{array}$ & + & + & - & $\begin{array}{l}\text { Fish: 46,XY.ish } \\
\text { 22q11.2(TUPLE1x1) }\end{array}$ \\
\hline $\begin{array}{l}13 \\
\mathrm{yr} / \mathrm{M}\end{array}$ & 3 months & GTC & Normal & $\begin{array}{l}\text { Well- } \\
\text { controlled } \\
\text { on PHB, } \\
\text { currently } \\
\text { off AED }\end{array}$ & Normal & + & $\begin{array}{c}\text { Borderline } \\
\text { intellectual } \\
\text { ability }\end{array}$ & ADHD & $4.9 \mathrm{Mb}$ \\
\hline $\begin{array}{l}20 \\
\mathrm{yr} / \mathrm{M}\end{array}$ & 8 years & GTC & Normal & $\begin{array}{l}\text { Well- } \\
\text { controlled } \\
\text { on VPA }\end{array}$ & $\begin{array}{l}\text { Pallidal and } \\
\text { subcortical } \\
\text { calcification }\end{array}$ & + & + & $\begin{array}{l}\text { Psychosis, } \\
\text { mood } \\
\text { disorder }\end{array}$ & $2.5 \mathrm{Mb}$ \\
\hline $\begin{array}{l}5 \\
\mathrm{yr} / \mathrm{M}\end{array}$ & 5 years & Focal & Normal & $\begin{array}{l}\text { Well- } \\
\text { controlled } \\
\text { on LEV }\end{array}$ & Normal & + & + & - & $652 \mathrm{~Kb}$ \\
\hline $\begin{array}{l}2.5 \\
\mathrm{yr} / \mathrm{M}\end{array}$ & 1 month & Focal & $\begin{array}{c}\text { BIRD+ED } \\
\text { over the } \\
\text { central } \\
\text { region }\end{array}$ & $\begin{array}{l}\text { Well- } \\
\text { controlled } \\
\text { on LEV }\end{array}$ & $\begin{array}{l}\text { Scattered } \\
\text { abnormalities in } \\
\text { the deep WM, } \\
\text { tiny lacunar } \\
\text { infarct at right } \\
\text { thalamus, } \\
\text { CSP, thin CC, } \\
\text { cerebral atrophy }\end{array}$ & + & + & - & $2.5 \mathrm{Mb}$ \\
\hline
\end{tabular}

M - Male, yr - Year, GTC - Generalized tonic-clonic, G - Generalized, BA - Background activity, BIRD - Brief ictal rhythmic discharge, ED -

Epileptiform discharge, BZO - Benzodiazepine, LEV - Levetiracetam, VPA - Valproic acid, AED - Antiepileptic drug, HSI - High signal intensity, WM - White matter, CSP - Cavum septum pellucidum, CC - Corpus callosum, NA - Not applicable, ADHD - Attention deficit hyperactivity disorder

intellectual ability to moderate intellectual disability. Two patients had a neuropsychiatric disorder, one had attention deficit hyperactivity disorder (ADHD), and one had a psychosis with a mood disorder.

Neurological, neuropsychiatric manifestations, and intellectual functioning in 22q11.2 DS. Twenty out of the 28 patients were reviewed and examined neurologically. Of these, 17/20 (85\%) were normocephalic, $3 / 20$ (15\%) were microcephalic, $11 / 20$ (55\%) were normotonic, $7 / 20$ (35\%) were hypotonic, $1 / 20(5 \%)$ were hemiplegic, $1 / 20(5 \%)$ had quadriparesis, $3 / 20(15 \%)$ had cerebellar dysfunction signs, and 2/20 (10\%) had upper motor neuron lesion signs.

The most prevalent neuropsychiatric manifestation of 22q11.2 DS was a developmental delay in 17 of the $28(60.7 \%)$ patients. Psychiatric disorders were found in $4 / 28(14.2 \%)$ patients with psychosis (one patient), ADHD (one patient), and autism spectrum disorder (2 patients) being prevalent.
Twelve of the 28 patients were had an IQ assessment conducted by a certified neuropsychologist using the Stanford-Binet Intelligence Scale $5^{\text {th }}$ edition. Three (25\%) had an average intellectual ability, 2 (16.7\%) had the borderline intellectual ability, 4 (33\%) had a mild intellectual disability, and $3(25 \%)$ had a moderate intellectual disability.

Brain imaging studies in 22q11.2 DS. Sixteen of the 28 patients with 22 q11.2 DS underwent neuroimaging. Of these, $10(62.5 \%)$ patients had abnormal neuroimaging findings (Figure 1), and 6 (37.5\%) patients had normal brain imaging. The abnormalities observed were: Thin corpus callosum (3 cases), neuronal migration disorders (2 cases) (Figure 2), cerebellar vermis hypoplasia (one case), ischemic insult in the cerebral white matter with atrophic changes (five cases), pallidal calcification (one case), the developmental venous anomaly of the cerebellum (one case), and cavum septum pellucidum and cavum vergae (4 cases) (Figure 2). 

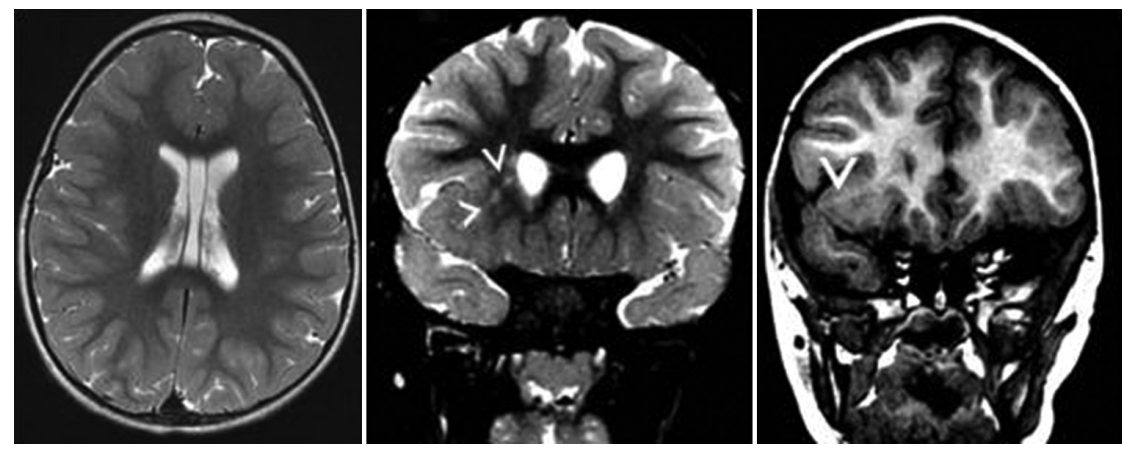

Figure 2 - Incidental finding in a patient with 22q11.2 DS of cavum septum pellucidum and vergae, with focal abnormal cortical development at the right inferior frontal gyrus with subcortical white matter signal abnormality extending to the lateral ventricle.

Genotype-neuro-phenotype correlation. Thirteen patients were diagnosed by FISH that showed a heterozygous deletion in the $22 \mathrm{q} 11.2$ region. A total of 13 patients were diagnosed by aCGH. Eleven patients had a deletion size of $2.5 \mathrm{Mb}$, one patient had a deletion size of $4.9 \mathrm{Mb}$, and one patient had a deletion size of $652 \mathrm{~kb}$. Interestingly, two patients were diagnosed with whole-exome sequencing because no deletion could be detected by aCGH mutations in the TBX1 gene.

Discussion. 22q11.2DS is a common microdeletion syndrome caused by the deletion of about $3 \mathrm{Mb}$ of DNA on chromosome 22 at position $22 \mathrm{q} 11.2$ in each cell with multisystem expression and an extremely heterogeneous phenotype. Epilepsy and neurologic or neuropsychiatric manifestations in $22 \mathrm{q} 11 \mathrm{DS}$ are frequent. ${ }^{3}$

Epilepsy is a frequent neurological disorder in patients with $22 \mathrm{q} 11.2 \mathrm{DS} .{ }^{4}$ Patients with $22 \mathrm{q} .11 \mathrm{DS}$ are at high risk to have both provoked and unprovoked seizures. The previous studies have shown that the prevalence of epilepsy in 22q11.2 DS ranges from $4.4 \%$ to $36.8 \%$. ${ }^{6}$ In addition, approximately $24 \%$ are reported to have symptomatic seizures. Interestingly, epilepsy in $22 \mathrm{q} 11$ DS is more often associated with developmental delay and intellectual disability. ${ }^{10}$ The underlying mechanism by which 22 q11.2 DS has a role in epileptogenesis is still largely not obvious, but multiple mechanisms have been suggested. First, mouse models of 22q11.2DS have demonstrated erratic synaptic plasticity that subsequently resulted in abnormal neuronal excitation-inhibition. ${ }^{6}$ Second, epilepsy in some patients is due to a structural brain lesion. Third, there are data suggesting that mutations in the Rab36 gene at position 22 q11.2 may prevent neurotransmitter processing or release. ${ }^{12}$

Similar to the previous studies, developmental delay and intellectual disability are frequent findings in $22 \mathrm{q} 11.2$ DS. Specific deficits of the numerical and visuospatial performance are also common and are seen in $30-40 \%$ of $22 \mathrm{q} 11.2 \mathrm{DS}$ patients. The neurodevelopmental and neuropsychiatric expression of 22 q11DS is highly variable, both inter- and intraindividually, and the expressions may differ over time. ${ }^{5,9}$ Furthermore, variable psychiatric disorders are diagnosed in $10-20 \%$ of patients. The neurobehavioral disorders of 22q11.2 DS include cognitive dysfunction, such as autism spectrum disorder, psychosis, and schizophrenia. ${ }^{5}$ A relationship between psychiatric manifestations in 22q11.2DS with structural alterations of the brain, including a reduction in the gray matter volume of the superior temporal lobe, widened lateral fissures, and posterior fossa reduction has also been reported previously. Frequent and chronic reduced cerebral perfusion due congenital heart disease are proposed to affect the alteration of early neurodevelopment and the high occurrence of neuropsychiatric diseases. ${ }^{10}$

The findings of the present study also have revealed the diversity of the central nervous system abnormalities, which ranged from minimal changes in the white matter to cortical development malformations, as identified in $62.5 \%$ of the cases. The previous studies have shown that cavum septum pellucidum and white matter high signal intensities are remarkably more common in patients with 22q11.2 DS and may constitute biomarkers for psychosis.7,11 The chronic cerebral hypoperfusion caused by congenital heart disease might explain the relatively high incidence of the scattered white matter signal abnormalities noted in our series as well as in other studies. An increased rate of cavum septum pellucidum, white matter high signal intensities, and abnormal vasculature were found in $22 \mathrm{q} 11.2$ deletion syndrome in comparison to a control group when analyzed using similar methods. ${ }^{11} \mathrm{~A}$ high rate of psychiatric disorders in patients with 22q11.2 DS 
with either cavum septum pellucidum or white matter abnormalities also was observed. Other findings include decreased cerebral brain volume, thinning of the corpus callosum, reduction in the cerebellar vermis size, and incidental cortical developmental abnormalities.

There are several limitations to this study. The first one is due to its retrospective nature. Not all patient data were available. The second limitation is missing of a control group regarding the neuropsychological evaluation.

In conclusion, Patients with $22 \mathrm{q} 11.2 \mathrm{DS}$ are at high risk to develop epilepsy, neuropsychiatric manifestations, and structural brain abnormalities. This indicates that this defined genetic locus is crucial for the development of the nervous system, and patients with 22q11.2 DS have genetic susceptibility to develop epilepsy. Diagnostic evaluation and early directed intervention for these phenotypes are important for improving patient outcomes.

Acknowledgment. We would like to thank Editage (www. editage.com) for English language editing.

\section{References}

1. McDonald-McGinn DM, Sullivan KE, Marino B, Philip N, Swillen A, Vorstman JA, et al. 22q11.2 deletion syndrome. Nat Rev Dis Primers 2015; 1; 15071.

2. McDonald-McGinn DM, Emanuel BS, Vermeesch JR, Scambler PJ. Molecular genetics of 22q11.2 deletion syndrome. Am J Med Genet A 2018; 176: 2070-2081.

3. Michaelovsky E, Frisch A, Carmel M, Patya M, Zarchi O, Green T, et al. Genotype-phenotype correlation in 22q11.2 deletion syndrome. BMC Med Genet 2012; 13: 122.
4. Basanagoud M, Nune S, Fultonzz S, Dayyat E, Wheless JW. Epilepsy in 22q11.2 deletion syndrome: A case series and literature review. Pediatr Neurol 2017; 76: 86-90.

5. Fiksinski AM, Schneider M, Murphy CM, Armando M, Vicari $\mathrm{S}$, Canyelles JM, et al. Understanding the pediatric psychiatric phenotype of 22q11.2 deletion syndrome. Am J Med Genet A 2018; 176: 2182-2191.

6. Eaton CB, Thomas RH, Hamandi K, Payne GC, Kerr MP, Linden DE, et al. Epilepsy and seizures in young people with 22q11.2 deletion syndrome: Prevalence and links with other neurodevelopmental disorders. Epilepsia 2019; 60: 818-829.

7. Bohm LA, Zhou TC, Mingo TJ, Dugan SL, Patterson RJ, Sidman JD, et al. Neuroradiographic findings in $22 \mathrm{q} 11.2$ deletion syndrome. Am J Med Genet A 2017; 173: 2158-2165.

8. Rogdaki M, Gudbrandsen M, McCutcheon RA, Blackmore CE, Brugger S, Ecker C, et al. Magnitude and heterogeneity of brain structural abnormalities in 22q11.2 deletion syndrome: A meta-analysis. Mol Psychiatry 2020; 2020: 638.

9. Jensen M, Kooy RF, Simon TJ, Reyniers E, Girirajan S, Tassone F. A higher rare $\mathrm{CNV}$ burden in the genetic background potentially contributes to intellectual disability phenotypes in 22q11.2 deletion syndrome. Eur J Med Genet 2018; 61: 209-212.

10. Kim EH, Yum MS, Lee BH, Kim HW, Lee HJ, Kim GH, et al. Epilepsy and other neuropsychiatric manifestations in children and adolescents with 22q11.2 deletion syndrome. $J$ Clin Neurol 2016; 12: 85-92.

11. Schmitt JE, Yi JJ, Roalf DR, Loevner LA, Ruparel K, Whinna $\mathrm{D}$, et al. Incidental radiologic findings in the $22 \mathrm{q} 11.2$ deletion syndrome. Am J Neuroradiol 2014; 35: 2186-2191.

12. Piccione M, Vecchio D, Cavani S, Malacarne M, Pierluigi M, Corsello G. The first case of myoclonic epilepsy in a child with a de novo 22q11.2 microduplication. Am J Med Genet A 2011; 155A: 3054-3059.

\section{Clinical Practice Guidelines}

Clinical Practice Guidelines must include a short abstract. There should be an Introduction section addressing the objective in producing the guideline, what the guideline is about and who will benefit from the guideline. It should describe the population, conditions, health care setting and clinical management/diagnostic test. Authors should adequately describe the methods used to collect and analyze evidence, recommendations and validation. If it is adapted, authors should include the source, how, and why it is adapted? The guidelines should include not more than 50 references, $2-4$ illustrations/tables, and an algorithm. 